Hall, Christopher J ORCID:

https://orcid.org/0000-0001-9038-1238 and Wicaksono, Rachel ORCID: https://orcid.org/0000-0003-0312-8491 (2020) Approaching ontologies of English. In: Hall, Christopher J ORCID: https://orcid.org/0000-0001-9038-1238 and Wicaksono, Rachel ORCID: https://orcid.org/0000-0003-0312-8491, (eds.) Ontologies of English. Conceptualising the language for learning, teaching, and assessment. Cambridge University Press, pp. 3-12

Downloaded from: http://ray.yorksj.ac.uk/id/eprint/4231/

The version presented here may differ from the published version or version of record. If you intend to cite from the work you are advised to consult the publisher's version: https://doi.org/10.1017/9781108685153.001

Research at York St John (RaY) is an institutional repository. It supports the principles of open access by making the research outputs of the University available in digital form. Copyright of the items stored in RaY reside with the authors and/or other copyright owners. Users may access full text items free of charge, and may download a copy for private study or non-commercial research. For further reuse terms, see licence terms governing individual outputs. Institutional Repository Policy Statement

\title{
RaY
}

Research at the University of York St John

For more information please contact RaY at ray@yorksj.ac.uk 


\section{Approaching ontologies of English}

Christopher J Hall and Rachel Wicaksono, York St John University

\section{Introduction}

This book is about the ways in which English is conceptualised in and for the domains of language learning, teaching, and assessment. Examining and being explicit about what we, as applied linguists, think English is-our ontologies of English-and how these ontologies underpin our educational ideologies and professional practices, should be an essential component of research in the discipline. Yet the nature of the 'EL' in ELT doesn't feature anywhere near as much as the ' $T$ ', and how English is conceptualised in schools tends to be debated more by educationalists than applied linguists. Teachers, learners, policy-makers and other stakeholders do have strong beliefs about what counts as English, who it belongs to, and how it should be taught, learned, and tested. In research we conducted with colleagues at a university in China (Hall et al., 2017), English teachers told us about the ways they conceptualised English as a global language and, more narrowly, as the subject they taught to undergraduate students. This is what one teacher said about the idea that English exists in a 'standardised' form (translated here from the original Mandarin):

Ms F: I believe in the existence of Standard English, perhaps it's some idealistic existence. [...] Maybe it doesn't really exist in reality. When we speak, the language is never standard. [...] Even native speakers can't speak Standard English - the idealistic, perfect, Standard English.

The teacher makes an explicit affirmation of her ontological commitment to a conceptualisation of English as an abstract entity. But she also subscribes to the existence of 'the language' in non-standard form, as used by native (and presumably non-native) speakers. Ontological commitments such as these are rarely examined inside or outside academia, yet the inconsistencies they often involve can have profound implications. (The obvious but far from trivial one here being: if Standard English only exists as an ideal, which not even native speakers can know and use, then why teach and test it as 'the language' in both L1 and L2 classrooms?)

We contend that the applied linguistic study of ontologies of English is necessary for two main reasons. First, it can help advance mutual understanding in both academic and professional domains. Leaving our conceptualisations unexamined and unacknowledged creates the potential for flawed reasoning, missed opportunities to recognise (in)compatibilities between different positions, and the perpetuation of ill-considered recommendations for policy and practice. Second, it can lead to better-informed educational policy and practice, potentially leading to broader social change. Helping teachers (and ultimately students and other stakeholders) to critically examine the ontological commitments underpinning their own ideologies and practices will enable them to more clearly define relevant learning goals. It will also inform efforts to expose and contest the social injustices currently faced by many English students, learners, and users. 
The book has been written primarily for scholars in applied linguistics and education, although from the outset we have asked contributors to try to make it as accessible as possible to external stakeholders. We are not assuming that all readers will be aware of the issues raised or familiar with the constructs discussed, and far less that they will be wellversed in the arcane ontological debates of philosophers. But inevitably the topic invites degrees of abstraction and theorisation which necessarily require technical terms (indeed, one of the editors is guilty of inventing several new ones). This chapter is intended to help readers from diverse backgrounds understand what the book is about and how to approach the chapters which follow. Section 2 situates this volume within broader ontological work outside and inside applied (and general) linguistics. Section 3 provides an overview of the individual chapters and the domains they address.

\section{What do we mean by 'ontologies of English?'}

Ontology is the metaphysical study of the nature of existence, addressing the superficially simple question of "What is there?" (Quine, 1980/1953, p. 1; our emphasis). It is concerned with (disputing) what kinds of things (entities, processes, properties, etc.) can be said to exist, what material or immaterial categories they belong to, whether they exist independently of human minds (and language), and the relationships between them (whether, for example, they are part of, instantiate, cause, or emerge from, other things). Since Quine (1980/1953), philosophers have also been interested in what ontological 'commitments' are articulated or presupposed by different theories and belief systems-i.e. what they assume, assert, or reject the existence of. Language has played a central role in ontological investigation, not so much with respect to its own status (although this does of course figure in the literature: cf., for example, Smith, 1987), but because ontological analysis inevitably involves issues of semantics and naming, and more specifically also because language is the principal medium through which immaterial entities (including named languages) are socially constructed. Indeed, in Searle's (1995) model of social ontology, all social institutions owe their existence to linguistic representation and expression.

Within contemporary linguistics, the ontological status of language and languages tends to be taken for granted, although there is extensive discussion of the issue in several key works of the late $20^{\text {th }}$ century (e.g. Harris, 1981; Katz, 1981; Chomsky, 1986; cf. Seargeant, 2010 for discussion of language ontology from a critical, historical perspective). Regarding English, linguists and applied linguists from very different orientations have expressly denied its existence, or questioned its ontological status. The generativists Isac and Reiss (2008: 15), for example, state: "If we take the mentalistic approach seriously, then we have to admit that there is no entity in the world that we can characterize as 'English.'" From the diametrically opposed perspective of critical applied linguistics, Pennycook (2007, p. 94), in a chapter entitled The myth of English as an International Language, asserts that "languages are political rather than ontological categories". The ontological status of English has become more prominent in applied linguistics as the effects of globalisation have drawn TESOL scholars to the World Englishes literature and the conceptual pluralisation this affords (cf. Kachru, 1992). More recently, research on English as an International Language (EIL; cf. Sharifian, 2009) and English as a Lingua Franca (ELF; cf. Seidlhofer, 2011) has 
prompted a shift in emphasis away from conceptualising English in terms of (non-native) varieties, and towards a view of the language as constitutive of (multilingual) practice.

Inevitably, ontological issues spill over into questions of epistemology (concerned with the status of knowledge, its sources and validity) and ideology (the sets of beliefs and behaviours which develop in individuals through socialisation into different cultural groups - the result of different epistemic traditions and dispositions). Different epistemologies lead to different ontological commitments, and different ontological commitments underpin different ideologies. Take, for example, the nature and status of what is known as 'Standard English', a concept thoroughly interrogated in this volume. Its ontological existence is presupposed by most citizens of the so-called 'Anglophone' countries (and by teachers like Ms F) not because they have direct sensory data which attest to it but because it is asserted in the national discourses of education, government, and the media. Knowledge of 'Standard English' is thus validated by an epistemology based on authority rather than evidence. And the ontological commitment to the existence of 'Standard English' is accompanied by the attribution of value to it, thus constituting an ideology in which it is accorded a superior status to other forms of English and a priviliged place in broader ideologies of national identity. The relationship is, of course, not unidirectional: the ideology and the epistemological tradition it is associated with also contribute to (arguably cause) the ontological commitment to its existence.

Likewise, ideological beliefs based on different epistemological practices can become ontologies. Van Dijk (2013, p. 177) writes: "As soon as ideological beliefs are accepted and taken for granted by all members of a community, by definition they are no longer ideologies but will count as knowledge in that community." The stakeholder communities we are concerned with here (linguists, applied linguists, learners and users, teachers, testers, policy makers, politicians, etc.) have beliefs about English which they take as facts, although these facts are not always consistent with each other, and context often dictates which fact will be invoked when. This leads inevitably to the realisation that ontologies are as relative and diverse as ideologies and epistemologies, at least in the case of mental/social entities like languages. Accordingly, then, the title of this volume refers to ontologies of English in the plural.

In a related sense, the word ontology is used as a count noun to refer to taxonomies of entities which are designated as existing in a particular domain or for a particular purpose, often organised hierarchically. In Artificial Intelligence, for example, ontologies specify what entities are symbolically represented in information systems and how they are related (for example in the Semantic Web; cf. Horrocks, 2008). The goal is to achieve maximal explicitness and also standardisation, so as to enable interoperability. In linguistics, in a new specialisation called ontolinguistics, there are similar efforts to standardise the set of concepts used in language description (Farrar, 2007). Our project is different. It is not the goal of this volume to agree (or seek agreement) on the ontological status or statuses of English, but rather to help make existing conceptualisations visible, exposing their commonalities and differences, destabilising some of them and inviting readers to conceptualise anew. 
In the sense entertained here, then, ontologies are cultural, susceptible to anthropological investigation. Indeed, there has been debate in anthropology recently about whether cultural differences are intrinsically ontological differences: the so-called 'ontological turn' (cf. Heywood, 2017). In a live debate on the motion 'Ontology is just another word for culture' held at the University of Manchester in 2008 (Carrithers, et al., 2010), Martin Holbraad argued that "[t]he anthropological task [...] is not to account for why ethnographic data are as they are, but rather to understand what they are-instead of explanation or interpretation, what is called for is conceptualization" (Carrithers, et al., 2010, p. 184). Accordingly, the reference in this volume's subtitle to "conceptualising the language" is both a description of what the chapters are trying to do, and also an invitation to readers.

The idea for this book arose from a BAAL/CUP Seminar held in 2015 at York St John University. One of the outcomes of that meeting was a call to "take a more activist stance to challenge dominant monolithic conceptualisations of English, chiefly by promoting awareness of users' actual knowledge and practices and the alternative ontologies that these imply" (Hall, 2017, p. 137). Lawson (2014, p. 22) states that the value of ontology "lies in bringing clarity and directionality, thereby facilitating action that is appropriate to context." The contexts of applied linguistics are diverse and uncountable, so the actions, like the conceptualisations, must be ongoing and permanent. If we think we can ever finish the ontological project, then we have not understood.

\section{How is the book organised?}

Following this introductory chapter and completing Part A, Hall proposes a framework which situates what we call English within two separate ontological categories: as a subset of the social and cognitive resources, processes, and products which instantiate the broader human language capacity; and as a series of reflexes of English national identity. His analysis pays particular attention to conceptualisations of the language as 'Standard English' and shows how this has had deleterious impacts which persist in both linguistics and educational practice. The main body of the book is divided into five main parts. These move from conceptualisations of English as a jointly social and cognitive phenomenon in and for L2 learning and teaching in Part $B$, to those which situate it as part of social practice in lingua franca settings and 'super-diverse' contexts in Parts E and F. The central chapters, in Parts C and $D$, examine the status and role of English in educational settings, as a school subject and medium, and as an object for L1 and L2 testing.

The chapters in Part B are united in conceptualising English in/for L2 learning and teaching as both cognitive and social in nature. Harder defines English in terms of the 'operational norms' which hold in social structures and to which community members' cognitive resources optimally adapt. He argues that 'Global English', as the union of all the existing operational norms, cannot constitute a learning goal, and that the 'practical reality' of Standard English may make it the only viable learning target at a collective level. While Harder is ultimately concerned with the implications of ontologies of English for teaching, Eskildsen focuses on what is actually learned, and how it's learned. He conceptualises English as inventories of constructions which underpin individual (cognitive) repertoires of resources for social action. He demonstrates how a combination of usage-based linguistics and conversation analysis can trace learners' development of English constructions through 
socially-situated, co-ordinated interaction, illustrated with data extracts from two classroom learners. In her chapter, Wicaksono reviews the social and cognitive arguments that have been advanced to categorise users of English as either 'native' or 'non-native' (primarily place and age). She points out that 'what counts as English' is taken as a given, in both the scholarly literature and in TESOL professional practice, and argues that the 'native'/'nonnative' distinction is untenable once the monolithic conceptualisations underpinning it are exposed. Her chapter is also a call to action, suggesting ways in which raising ontological awareness can be embedded in teacher training and hiring practices.

The chapters in Part $\mathrm{C}$ consider the ontological status of English as it is understood in schools. In a review of the ways in which school subject English (SSE) has evolved over the past 150 years or so in England, Goodwyn highlights the tensions between state conceptualisations, in which English (predominantly English literature) is an aspect of cultural heritage existing primarily in the textual domain, and the conviction of teachers that English should constitute a resource for individual student growth. Goodwyn identifies the practical reality of teaching as a third ontological plane, where both conceptualisations of SSE are tempered by increasing external control and consequent self-regulation. In the following chapter, Roberts picks up the baton from Goodwyn to provide a critical analysis of the conceptualisation of English underpinning England's national curriculum for SSE. She interprets the ontological status of English in the curriculum as knowledge (which students must have), contrasting this with English as learning (which students can do). She argues for a conceptualisation of SSE closer to the 'god-like science' of Frankenstein's creature, characterised by interpretation, creation, and emotion. Cunningham's chapter extends the ontological critique of educational conceptualisations of English beyond the literary focus of SSE to the broader notion of 'good English' in schools, as held by teachers of all subjects. She calls attention to the way in which ontologies of English which privilege the 'standard variety' marginalise both pupils with unstandardised Englishes and those with languages beyond English ('EAL' students), with the former (conceived as 'users') often constructed more negatively than the latter (conceived as 'learners').

Part D addresses how English is (or should be) conceptualised for assessment. Harsch's chapter departs from the key recognition that learning targets tend to be based on norms which differ from those governing most international communication in English. Like Harder, she adopts a pragmatic stance with respect to the value of standard English for some learning contexts and needs, advocating the revised scales of the Common European Framework (CEFR) as a basis for developing appropriate tasks and goals, and the use of corpora and discourse analysis to identify what to assess. Nakatsuhara, Taylor and Jaiyote are concerned with the effects on test validity of the porous nature of English as a testable object. They present data from studies of the role of L1 influence in an international test of general English and a national ESP test to demonstrate how conceptualisations of English in/for global and local contexts can or should be relevant to test-taker needs and, once again, argue for a pragmatic approach. Goddard's chapter takes a more critical perspective on English assessment, returning to issues raised in Part $C$ to examine how the SSE curriculum (in England) is being increasingly dominated by a culture of testing which conceptualises English as either a decontextualised linguistic system or as a set of texts which reflect national cultural heritage. Goddard shows how politically-driven reforms have 
led to pupils encountering ontologies of English which lack consistency and relevance for their future needs.

The contributors to Part E examine how global lingua franca usage has led to reconceptualisations of English which present new challenges for educational contexts. The first chapter, by Schaller-Schwaner and Kirkpatrick, conceptualises English as a lingua franca (ELF) as an aspect of multilingual practice, in which speakers make linguistic choices contingent on a series of contextual factors. This contingency is illustrated in two contrasting multilingual settings, one where English became the lingua franca by official mandate and the other where it emerged 'bottom-up' in opposition to official policy. Baker's chapter reaffirms the multilingual nature of lingua franca English but argues that more attention should be paid to its multicultural dimension, especially in global ELT. He argues that communicative competence in ELF usage not only blurs the differences between named languages, but also constitutes 'transcultural' practice which, equally, 'transgresses and transcends' preassumed cultural boundaries. In the following chapter, Page presents data from Japanese volunteers working in international development projects which shed light on the complex ontologies of English that can be inferred from their learning/use of the language for/in global lingua franca contexts. He observes how contextual factors can cause their conceptualisations of English to move along a 'standards-based' to 'intelligibilitybased' continuum, and advocates that teachers need to be aware of, and be able to respond to, this ontological incongruity.

The final set of contributions, in Part F, all pursue the view, anticipated in several previous chapters, that English for learning and teaching is now most usefully conceptualised as social practice. Canagarajah looks outside linguistics and applied linguistics for a conceptualisation of language in communication informed by 'flat ontology', a 'new materialist' orientation which stresses the emergence of meaning and structure from collaborative, distributed social practices. Using processual and spatial metaphors (the functional assemblage of bricolage; the non-linear, decentring networks of rhizomes), he sets out an approach in which English is an ideology, thus undermining traditional pedagogical preoccupations with 'representational' competence. Consistent with Canagarajah's charge, Sharples argues that the dominant ('settled') ontologies of English contribute to educational policy and pedagogical practice which are effectively failing the growing populations of young migrants ('EAL students') in the global North. He calls instead for a 'mobile orientation' in which course structures and curriculums become more flexible, and classrooms become places where individual trajectories intersect and prior experiences are valued, so that pupils can work towards mainstream discourse norms without being marginalised and having their own linguistic repertoires delegitimised. In her chapter, Badwan shows how the 'standard ontology' of monolithic English serves the commercial interests of the publishing houses (who purvey it in textbooks, tests, and access to global academic content), but does a disservice to mobile students in study abroad contexts (who encounter a sociolinguistic reality for which the myths they have been sold ill prepare them). She advocates a more honest pedagogy involving 'conscious learning' to expose the myths and allow learners to adopt appropriate English resources into their communicative repertoires. 
Finally, in Part E, Pennycook provides critical commentary on the issues raised in the volume. He highlights the fact that most chapters seek to understand prevailing conceptualisations of English and to advocate a 'plurilithic' stance in the different domains they address. A more radical step, he suggests, is to question the ontological status of language itself and therefore of English, which he casts as a 'second-order' curricular, cultural, and political convenience. In the last chapter, Wicaksono and Hall take stock and consider the uses of the project.

References

Carrithers, M., Candea, M., Sykes, K., Holbraad, M. and Venkatesan, S. (2010). Ontology is just another word for culture: motion tabled at the 2008 meeting of the Group for Debates in Anthropological Theory, University of Manchester. Critique of Anthropology, 30(2), 152-200.

Chomsky, N. (1986). Knowledge of language. New York: Praeger.

Farrar, S. (2007). Using 'Ontolinguistics' for language description. In Schalley, A. C. and Zaefferer, D. (eds), Ontolinguistics: How ontological status shapes the linguistic coding of concepts (pp. 175-191). Berlin: Walter de Gruyter.

Hall, C. J. (2017). BAAL/CUP Seminar 2015. (De)Constructing Englishes: Exploring the implications of ontologies of the language for learning, teaching and assessment. Language Teaching, 50(1), 135-7.

Hall, C. J., Wicaksono, R., Liu, S., Qian, Y. and Xu, X. (2017). Exploring teachers' ontologies of English. Monolithic conceptions of grammar in a group of Chinese teachers. International Journal of Applied Linguistics, 27(1), 87-109.

Harris, R. (1981). The language myth. London: Duckworth.

Heywood, P. (2017). The ontological turn. In Stein, F., Lazar, S., Candea, M., Diemberger, H., Robbins, J., Sanchez, A. and Stasch, R. (eds), The Cambridge encyclopedia of anthropology. http://doi.org/10.29164/17ontology.

Horrocks, I. (2008). Ontologies and the semantic web. Communications of the ACM, 51(12), 58-67.

Isac, D. and Reiss, C. (2008). I-Language. An introduction to linguistics as cognitive science. Oxford: Oxford University Press.

Kachru, B. B. (ed.) (1992) The other tongue. English across cultures (2nd edn). Urbana, IL: University of Illinois Press.

Katz, J. (1981). Language and other abstract objects. Totowa, NJ: Rowman and Littlefield. Lawson, T. (2014). A conception of social ontology. In Pratten, S. (ed.), Social ontology and modern economics (pp. 19-52). London: Routledge.

Pennycook, A. (2007). The myth of English as an International Language. In Makoni, S. and Pennycook, A. (eds), Disinventing and reconstituting languages (pp. 90-115). Clevedon, UK: Multilingual Matters.

Quine, W. (1980/1953). From a logical point of view (2 ${ }^{\text {nd }}$ edn). Cambridge, MA: Harvard University Press.

Seidlhofer, B. (2011). Understanding English as a Lingua Franca. Oxford: Oxford University Press.

Seargeant, P. (2010). The historical ontology of language. Language Sciences, 32(1), 1-13.

Searle, J. R. (1995). The construction of social reality. New York: Simon and Schuster. 
Sharifian, F. (Ed.) (2009). English as an International Language. Perspectives and pedagogical issues. Bristol: Multilingual Matters.

Smith, B. (1987). Husserl, language and the ontology of the act. In Buzzetti, D. and Ferriani, M. (eds), Speculative grammar, Universal Grammar, and philosophical analysis of language (pp. 205-227). Amsterdam: John Benjamins.

Van Dijk, T. A. (2013). Ideology and discourse. In Freeden, M., Tower Sargent, L. and Stears, M. (eds), The Oxford handbook of political ideologies (pp. 175-196). Oxford: Oxford University Press. 